\title{
Brain serotonergic and dopaminergic modulators, perceptual responses and endurance exercise performance following caffeine co-ingested with a high fat meal in trained humans
}

\author{
Marios P Hadjicharalambous 1,2, Liam P Kilduff2,3 and Yannis P Pitsiladis*2
}

\begin{abstract}
Background: The present study examined putative modulators and indices of brain serotonergic and dopaminergic function, perceptual responses, and endurance exercise performance following caffeine co-ingested with a high fat meal.

Methods: Trained humans $(n=10)$ performed three constant-load cycling tests at $73 \%$ of maximal oxygen uptake $\left(\mathrm{VO}_{2} \mathrm{max}\right)$ until exhaustion at $10^{\circ} \mathrm{C}$. Prior to the first test, subjects consumed a $90 \%$ carbohydrate meal (Control trial) and for the remaining two tests, a 90\% fat meal with ( $F C$ trial) and without ( $F$ trial) caffeine.

Results: Time to exhaustion was not different between the $F$ and FC trials $(P>0.05)$; [Control trial: 116(88-145) min; $F$ trial: 122(96-144) min; FC trial: 127(107-176) min]. However, leg muscular discomfort during exercise was significantly lower on the $\mathrm{FC}$ relative to $\mathrm{F}$ trial $(P<0.01)$. There were no significant differences between $\mathrm{F}$ and $\mathrm{FC}$ trials in key modulators and indices of brain serotonergic (5-HT) and dopaminergic (DA) function [(i.e. plasma free and total tryptophan (Trp), tyrosine (Tyr), large neutral amino acids (LNAA), Trp:LNAA ratio, free-Trp:Tyr ratio, total Trp:Tyr ratio, and plasma prolactin] $(P>0.05)$ with the exception of plasma free-Trp:LNAA ratio which was higher at 90 min and at exhaustion during the FC trial $(P<0.05)$.
\end{abstract}

Conclusions: Neither brain 5-HT nor DA systems would appear to be implicated in the fatigue process when exercise is performed without significant thermoregulatory stress, thus indicating fatigue development during exercise in relatively cold temperatures to occur predominantly due to glycogen depletion.

\section{Background}

Following the exclusion of caffeine from the World AntiDoping Agency list of prohibited substances, there was an increased interest in freely using caffeine, particularly by endurance athletes, as an ergogenic aid supplement [1]. It was previously reported that caffeine, at doses of (3-9 $\mathrm{mg} \cdot \mathrm{kg}^{-1}$ ) body mass, enhances performance by altering substrate availability; more specifically by promoting adipose tissue lipolysis and fatty acids oxidation from skeletal muscle which contributes in enhancing carbohydrate $(\mathrm{CHO})$ sparing $[2,3]$. Recently however, a consider-

\footnotetext{
*Correspondence: Y.Pitsiladis@bio.gla.ac.uk

2 Integrative and Systems Biology, Faculty of Biomedical and Life Sciences (FBLS), University of Glasgow, Glasgow, UK

Full list of author information is available at the end of the article
}

able amount of evidence has cast doubts over the CHOsparing effect of caffeine during endurance exercise [e.g. $[4,5]$. In addition, caffeine has been shown to improve short duration high-intensity exercise performance where glycogen depletion is clearly not the primary cause of fatigue [e.g. [6,7]. Therefore, it is possible that the ergogenic effect of caffeine reflects a stimulant action on the CNS $[8,9]$ rather than the traditional CHO-sparing effect during endurance exercise.

Animal studies, for example, suggest that caffeine has the potential to reduce brain serotonin (5-HT) synthesis by inhibiting tryptophan hydroxylase, the rate limiting enzyme of central 5-HT biosynthesis [10], and/or to reduce brain 5-HT:dopamine (DA) ratio by blocking adenosine $\alpha_{1}$ and $\alpha_{2}$ receptors within the CNS, which 
otherwise inhibit brain DA synthesis [8,11]. Consequently, one plausible explanation for the reduced effort perception observed following caffeine ingestion [12] may be due to the increased brain DA levels [8] and/or to the reduced brain 5-HT response [10]. This is consistent with the hypothesis that a high brain 5-HT:DA ratio may favour increased subjective effort and central fatigue, while a low 5-HT:DA ratio may favour increased arousal and central motivation $[13,14]$.

Newsholme et al. [15] proposed that an increase in activity of 5-HT neurons in various brain regions such as the midbrain and hypothalamus may contribute to fatigue development during prolonged exercise, a mechanism commonly referred as the "central fatigue hypothesis". 5-HT is synthesised from the essential amino acid precursor tryptophan (Trp) and during periods of high 5HT activity, the rate of 5-HT synthesis can be influenced by the uptake of Trp from plasma [16]. A rise in plasma free fatty acids (FFA) concentration displaces Trp from albumin raising the Trp fraction in plasma, thus increasing brain Trp uptake and arguably $5-\mathrm{HT}$ synthesis $[17,18]$. Subsequently, the net effect of ingesting caffeine prior to exercise would be to increase central DA release and/or to counterbalance the high 5-HT:DA ratio reducing therefore effort perception induced by the exercise stress [14]. Consequently, the aim of the present study was to examine the relationship between peripheral modulators of brain 5-HT and DA function, perceptual responses and endurance performance during prolonged submaximal exercise to volitional fatigue, following caffeine co-ingested with a high fat meal in well-trained cyclists. The pre-exercise high fat meal was employed to imitate physiologically the metabolic effects of caffeine in an attempt to distinguish between the potential peripheral and/or central effects of caffeine.

\section{Methods Participants}

Ten endurance-trained male cyclists [age $25 \pm 6$ years; height $1.82 \pm 0.07 \mathrm{~cm}$; body mass $74.34 \pm 8.61 \mathrm{~kg}$; maximal oxygen uptake $\left.\left(\mathrm{VO}_{2} \mathrm{max}\right) 62 \pm 5 \mathrm{ml} \cdot \mathrm{kg}^{-1} \cdot \mathrm{min}^{-1}\right]$ volunteered to participate in the present study. All participants gave their written informed consent to take part in the study, which was approved by the local research ethics committee.

\section{Experimental design}

The participants initially underwent ramp incremental exercise $\left(15-20 \mathrm{~W} \cdot \mathrm{min}^{-1}\right)$ to the limit of tolerance using an electrically braked cycle ergometer (Bosch Erg-551 Forckenbecksti, Berlin, Germany) to determine $\mathrm{VO}_{2} \max$ and the maximal work rate. The participants were required to undertake three cycled exercise tests to exhaustion, at an ambient temperature of $10^{\circ} \mathrm{C}$ with $70 \%$ relative humidity, at $\sim 73 \%$ of $\mathrm{VO}_{2} \max$ (a work-rate equivalent to $63 \% \pm 5$ of each individual's maximal work rate).

The participants underwent at least two familiarisation trials prior to the three exercise tests in order to become familiarised with the exercise protocol and experimental procedures. During the familiarisation period (i.e., 3 days prior to the second familiarisation trial) each participant's normal energy intake and diet composition were determined from weighted dietary intake data using a computerised version of the food composition tables of McCance and Widdowson (revised by Holland et al., [19]). Based on this information, subjects were prescribed a high (70\%) $\mathrm{CHO}$ diet throughout the study period (for twelve consecutive days), intended to increase and maintain liver and muscle glycogen concentration before each of the main exercise trials [20]. The $70 \% \mathrm{CHO}$ diet was isoenergetic with each participant's normal daily energy intake, and food items prescribed were based predominantly on each participant's normal diet.

Four hours prior to the first exercise test the participants consumed a standardised high $\mathrm{CHO}$ meal (Control trial: $90 \%$ of energy intake in the form of $\mathrm{CHO}$ ). The control trial was always performed first and therefore, this trial was not included in the randomization, and hence in the statistical analysis. Four hours before the second and third exercise tests, the participants consumed a standardised high fat meal (1g fat $\cdot \mathrm{kg}^{-1}$ body mass; $90 \%$ of energy intake in the form of fat). All experimental meals were isoenergetic and prepared by the same investigator. One hour before exercise following the high fat meals (second and third tests), participants ingested, in a crossover double blind manner, capsules containing either caffeine (7.5 mg.kg-1 body mass; FC trials) or an equivalent amount of placebo (calcium carbonate; $\mathrm{F}$ trial). The participants, who were habitually moderate caffeine users (from none to two cups of coffee per day), were required to maintain normal training habits throughout the study period, but refrain from strenuous training and consumption of alcohol or caffeine-containing products $48 \mathrm{hrs}$ prior to each exercise test.

\section{Procedures}

All exercise tests were carried out between 16:00-21:00 h following a $4 \mathrm{~h}$ fast, where water was allowed ad libitum. Participants reported to the laboratory $11 / 2 \mathrm{~h}$ before the start of exercise, and on the two fat trials consumed capsules containing caffeine or placebo, $3 \mathrm{~h}$ after consuming the fat meal. Once body mass was measured, participants were seated comfortably with their right hand and forearm immersed for $15 \mathrm{~min}$ in water at $42-44^{\circ} \mathrm{C}$, to achieve arterialization of the venous blood [21]. Following this, an $18 \mathrm{G}$ venous cannula was introduced into a superficial 
vein on the dorsal surface of the heated hand and a resting blood sample was obtained. Further blood samples were obtained at $15 \mathrm{~min}$ intervals throughout exercise until the 90 min time-point and at exhaustion. Participants were transferred to the climatic chamber (ambient temperature $10.2 \pm 0.2^{\circ} \mathrm{C}$; relative humidity $69.8 \pm 1.0 \%$; air velocity of approximately $3.6 \mathrm{~m} \cdot \mathrm{s}^{-1}$ ) and began exercise within $1 \mathrm{~min}$ of entering. The exercise intensity and ambient temperature were chosen to induce fatigue that would be most likely due to muscle glycogen depletion rather than the result of some failure in the thermoregulatory system [22]. The cannula was kept patent by a slow $\left(\sim 0.5 \mathrm{ml} \cdot \mathrm{min}^{-1}\right)$ infusion of isotonic saline between samples during both experiments. Arterialization of the venous blood was maintained throughout exercise by heating the hand using an infrared lamp. The participants ingested $7.14 \mathrm{~g} \cdot \mathrm{kg}^{-1}$ and $2.14 \mathrm{~g} \cdot \mathrm{kg}^{-1}$ of water at rest and every $15 \mathrm{~min}$ throughout exercise, respectively. The participants were asked to maintain a pedal cadence of 60-80 rev? $\mathrm{min}^{-1}$ throughout the test; exhaustion was defined as the point at which the subject could no longer maintain the pedal cadence above $60 \mathrm{rev} \cdot \mathrm{min}^{-1}$

Expired gas was collected in Douglas bags for $5 \mathrm{~min}$ at rest, and thereafter $1 \mathrm{~min}$ collections were obtained every 15 min during exercise. Expired gases were analysed within 5 min of collection for oxygen uptake $\left(\mathrm{VO}_{2}\right)$ (Servomex 570A, East Sussex, UK) and carbon dioxide production $\left(\mathrm{VO}_{2}\right)$ (Servomex 1400 B4, East Sussex, UK), volume (dry gas meter, Harvard Apparatus Ltd., Hertfordshire, UK) and temperature (C6600 10-Channel Microprocessor, Comark, Hertfordshire, UK). All gas volumes were corrected to STPD. Barometric pressure was measured using a standard mercury barometer.

The participants were asked to rate "shortness of breath" (breathlessness/dyspnoea) and "leg effort" (leg exertion) using Borg's 6 - 20 RPE scale [23] every $10 \mathrm{~min}$ during exercise until exhaustion. Heart rate (Polar Sport Tester, Polar Electro Oy, Finland) was also recorded every 10 min during exercise until exhaustion. Following exercise, participants were weighed and loss of body mass was calculated, after correcting for water consumed during exercise. Time to exhaustion was recorded, but withheld from the participant until all trials had been completed and the participant had answered the post-intervention questionnaire. Participants were asked: (1) to predict the order of treatments received during the study; (2) to nominate the treatment they perceived produced their best performance; and (3) to indicate which trial they found the most difficult.

\section{Blood treatment and analysis}

Blood $(10 \mathrm{ml})$ was drawn into dry syringes and dispensed into tubes containing $\mathrm{K}_{3}$ EDTA and the remaining into tubes containing no anticoagulant for later use. Duplicate aliquots $(400 \mu \mathrm{l})$ of whole blood from the $\mathrm{K}_{3}$ EDTA tubes were rapidly deproteinized in $800 \mu \mathrm{l}$ of ice-cold $0.3 \mathrm{~mol} \cdot \mathrm{l}^{-1}$ perchloric acid. After centrifugation, the supernatant was used for the measurement of glucose, lactate and pyruvate using standard enzymatic methods with spectrophotometric detection (Mira Plus, ABX Diagnostics, Montpellier, France). A further aliquot of blood was centrifuged and the plasma obtained was separated and used for the measurement of free fatty acids (colorimetric method, Roche Diagnostics GmbH, Germany) and concentrations of amino acids by HPLC using fluorescence detection and pre-column derivitisation with $18 o$-phthalaldehyde (Hypersel Amino acid method, ThermoHypersil-Keystone, Runcorn, UK). Free-Trp was separated from protein-bound Trp by filtering plasma through 10,000 NMWL 'nominal molecular weight limit' cellulose filters (Ultrfree-MC filters, Millipore Corporation, USA) during centrifugation at $5000 \mathrm{~g}$ for $60 \mathrm{~min}$ at $4^{\circ} \mathrm{C}$. Prior to centrifugation, filters were filled with a $95 \% \mathrm{O}_{2}-5 \% \mathrm{CO}_{2}$ mixture in order to stabilize $\mathrm{pH}$. The blood in tubes without anticoagulant was allowed to clot and then centrifuged; the serum collected was used for the measurement of prolactin (Prl) by sandwich magnetic separation assay (Technicon Immuno 1 System, Bayer Diagnostics, Newbury, UK).

\section{Statistical analysis}

Data are expressed as the mean \pm SD following a test for the normality of distribution. For data that violated the assumptions for parametric analyses (i.e. equality of variance and normality of distribution) non-parametric analyses was carried out and these data were expressed as the median (range). As all participants completed the control trial first and were subsequently assigned to the two fat trials in randomized order, statistical analysis was carried out on the two fat trials. Statistical analysis of the data was carried out using a two-factor analysis of variance (treatment $\times$ time) for repeated measures followed by Student's t-test for paired data, where necessary. Time to exhaustion was not normally distributed and was therefore analysed using the Wilcoxon signed rank test. Statistical significance was declared at $P<0.05$.

\section{Results}

\section{Time to Fatigue and ratings of perceived exertion}

Time to fatigue during constant-load exercise was similar between the two fat trials [(Control trial: 116(88-145) min; F trial: 122(96-144) min; FC trial: 127(107-176) $\mathrm{min})]$. Ratings of perceived leg exertion were significantly lower $\left(\mathrm{F}_{(1,9)}=11.985, P=0.007\right)$ during constant-load exercise on the $\mathrm{FC}$ compared with the $\mathrm{F}$ trial while ratings of perceived breathlessness were not different between 


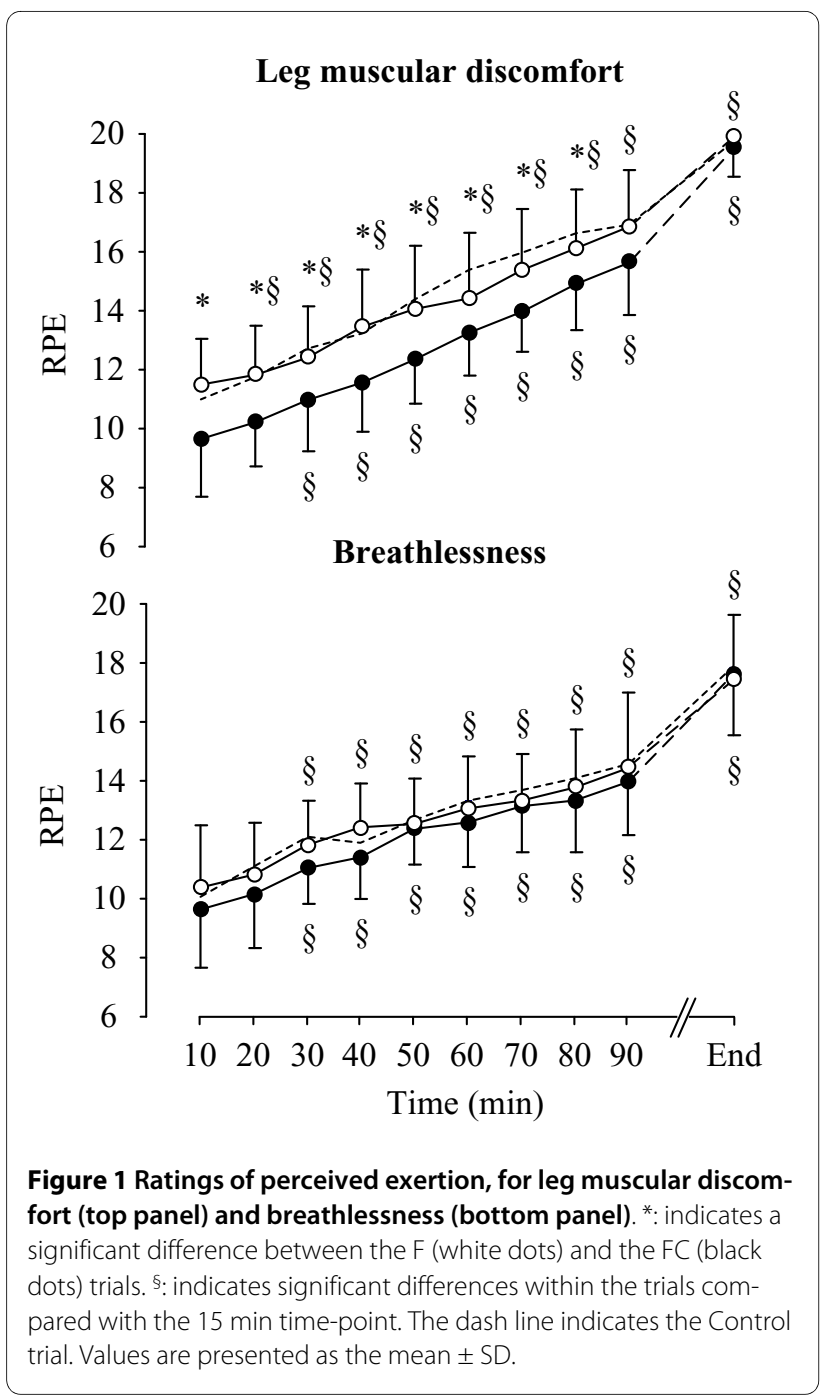

the trials (Figure 1). Six out of ten subjects ranked the FC as the easiest trial (one subject was unsure).

\section{Cardiopulmonary variables and fuel oxidation}

$\dot{\mathrm{V}} \mathrm{O}_{2}$ increased over time on both trials and it was higher on the FC trial compared with the $\mathrm{F}$ trial $\left(\mathrm{F}_{(1,9)}=7.980, P\right.$ $=0.02)$ (Table 1). Minute ventilation $(\dot{\mathrm{V}} \mathrm{E})$ was significantly higher on the $\mathrm{FC}$ trial compared with $\mathrm{F}$ trial $\left(\mathrm{F}_{(1,9)}=\right.$ 10.917, $P=0.009$ ) and there was a progressive increase in $\dot{\mathrm{V}} \mathrm{E}$ and $\dot{\mathrm{V}} \mathrm{Co}_{2}$ over time on both fat trials; no differences in respiratory exchange ratio (RER) were found between $\mathrm{F}$ and FC trials (Table 1). Heart rate and total $\mathrm{CHO}$ and fat oxidation (FC trial: $371 \pm 82 \mathrm{~g} \mathrm{CHO}, 77 \pm 50 \mathrm{~g}$ fat; F trial: $388 \pm 90 \mathrm{~g} \mathrm{CHO}, 52 \pm 23 \mathrm{~g}$ fat; Control trial: $367 \pm$ $87 \mathrm{~g} \mathrm{CHO}, 39 \pm 23 \mathrm{~g}$ fat) were not different between the $\mathrm{F}$ and FC trials.

\section{Plasma amino acids, prolactin and blood metabolites}

There were no significant differences between $\mathrm{F}$ and FC trials in total [Trp], [Tyr], [LNAA], total [Trp]:[LNAA] ratio and total [Trp]:[Tyr] ratio (Table 2). However, there was a tendency for plasma free-[Trp] $(P=0.064)$ and free[Trp]:[Tyr] ratio $(P=0.066)$ to be higher on the FC relative to $\mathrm{F}$ trial (Figure 2). Plasma free-[Trp]:[Tyr] ratio did not change over time. Plasma free-[Trp] increased over time in both trials. The plasma free-[Trp]:[LNAA] ratio was significantly higher at $90 \mathrm{~min}$ and at exhaustion on the FC relative to $\mathrm{F}$ trial $(P=0.029)$ (Figure 2). The plasma [Prl] was not different between trials (Figure 3). The peak plasma [Prl] value was detected at exhaustion. A higher plasma [FFA] was found on the FC compared to the $\mathrm{F}$ trial $\left(\mathrm{F}_{(1,9)}=10.959, P<0.01 P=0.009\right)$ at rest and during exercise (Figure 4). Higher blood [glucose] $\left(\mathrm{F}_{(1,9)}=\right.$ 23.329, $P<0.001)$, [lactate] $\left(\mathrm{F}_{(1,9)}=13.823, P<0.01\right)$ and [pyruvate] $\left(\mathrm{F}_{(1,9)}=35.262, P<0.001\right)$ was found throughout exercise on the FC compared with the F trial (Table 3). There was no correlation between time to exhaustion and any of the other depended variables.

\section{Reported side effects}

Four out of the ten subjects experienced slight gastrointestinal discomfort; three following the high fat meal with caffeine and one following the high fat meal alone. One subject experienced more severe side effects following the high fat meal and caffeine ingestion $30 \mathrm{~min}$ following exercise. These effects included loss of consciousness, dizziness, abdominal pain, nausea and vomiting. These effects disappeared shortly after the experience.

\section{Discussion}

The present study examined the relationship between the putative modulators and indices of brain serotonergic and dopaminergic function, effort perception and endurance exercise performance in a relatively cold $\left(10^{\circ} \mathrm{C}\right)$ environment following caffeine co-ingestion with a high fat meal in well-trained humans. The results presented here do not support any significant involvement of the putative modulators of brain serotonergic and dopaminergic function in the exercise fatigue process during submaximal constant-load exercise at low ambient temperatures. This lack of involvement of the putative modulators of 'central fatigue' was observed despite a significant reduction in effort perception following caffeine ingestion. It is difficult however, to explain why the subjects in the present experiment perceived it easier to exercise with caffeine than without, particularly when one considers the accompanying elevation in blood [lactate], $\dot{\mathrm{V}} \mathrm{O}_{2}$, and $\dot{\mathrm{V}} \mathrm{E}$ that typically would be expected to augment, rather than attenuate effort perception [23]. It is possible that caffeine 


\begin{tabular}{|c|c|c|c|c|c|c|c|c|}
\hline \multirow[b]{2}{*}{ Variables } & \multirow[b]{2}{*}{ Trials } & \multicolumn{7}{|c|}{ Exercise Time (min) } \\
\hline & & Rest & 15 & 30 & 45 & 60 & 75 & 90 \\
\hline \multirow{3}{*}{$\dot{\mathrm{V}} \mathrm{O}_{2}\left(\mathrm{~L} \cdot \mathrm{min}^{-1}\right)$} & Control & $.3 \pm .04$ & $3.2 \pm 0.4$ & $3.2 \pm 0.4$ & $3.4 \pm 0.5$ & $3.4 \pm 0.5$ & $3.5 \pm 0.6$ & $3.4 \pm 0.4$ \\
\hline & $\mathrm{F}$ & $.3 \pm .03$ & $3.1 \pm 0.4$ & $3.2 \pm 0.4^{\S}$ & $3.2 \pm 0.4$ & $3.4 \pm 0.4^{\S}$ & $3.4 \pm 0.5^{\S}$ & $3.5 \pm 0.5^{\S}$ \\
\hline & FC & $.4 \pm .07$ & $3.3 \pm 0.3$ & $3.4 \pm 0.4$ & $3.4 \pm 0.5^{\S}$ & $3.5 \pm 0.5^{\S}$ & $3.6 \pm 0.5^{* \S}$ & $3.6 \pm 0.5^{\S}$ \\
\hline \multirow{3}{*}{$\dot{\mathrm{V}} \mathrm{CO}_{2}\left(\mathrm{~L} \cdot \mathrm{min}^{-1}\right)$} & Control & $.3 \pm .04$ & $3.0 \pm 0.5$ & $3.0 \pm 0.5$ & $3.1 \pm 0.5$ & $3.1 \pm 0.5$ & $3.2 \pm 0.7$ & $3.1 \pm 0.5$ \\
\hline & $\mathrm{F}$ & $.3 \pm .03$ & $3.0 \pm 0.4$ & $3.1 \pm 0.4$ & $3.1 \pm 0.4$ & $3.2 \pm 0.4^{\S}$ & $3.2 \pm 0.4^{\S}$ & $3.3 \pm 0.5^{\S}$ \\
\hline & FC & $.3 \pm .05$ & $3.0 \pm 0.3$ & $3.1 \pm 0.4$ & $3.1 \pm 0.4$ & $3.2 \pm 0.4$ & $3.3 \pm 0.5^{\S}$ & $3.2 \pm 0.4$ \\
\hline \multirow[t]{3}{*}{$\dot{\mathrm{V}} \mathrm{E}\left(\mathrm{L} \cdot \mathrm{min}^{-1}\right)$} & Control & $8.0 \pm 2$ & $66 \pm 1$ & $69 \pm 1$ & $73 \pm 1$ & $74 \pm 1$ & $78 \pm 1$ & $76 \pm 9.0$ \\
\hline & $\mathrm{F}$ & $8.0 \pm 1$ & $66 \pm 1$ & $68 \pm 1$ & $70 \pm 1^{\S}$ & $73 \pm 1 \S$ & $76 \pm 1^{\S}$ & $78 \pm 14 \S$ \\
\hline & FC & $10 \pm 2$ & $70 \pm 6$ & $73 \pm 8^{* \S}$ & $75 \pm 1 * \S$ & $79 \pm 1 * \S$ & $81 \pm 1 * \S$ & $81 \pm 10^{\S}$ \\
\hline \multirow[t]{3}{*}{ RER } & Control & $.89 \pm .08$ & $.95 \pm .3$ & $.95 \pm .03$ & $.94 \pm .05$ & $.94 \pm .03$ & $.93 \pm .04$ & $.93 \pm .02$ \\
\hline & $\mathrm{F}$ & $.87 \pm .10$ & $.95 \pm .3$ & $.94 \pm .03$ & $.93 \pm .04$ & $.93 \pm .03^{\S}$ & $.93 \pm .02$ & $.91 \pm .03^{\S}$ \\
\hline & FC & $.87 \pm .07$ & $.93 \pm .4$ & $.91 \pm .03^{\S}$ & $.91 \pm .05$ & $.91 \pm .05$ & $.90 \pm .06$ & $.88 \pm .05^{\S}$ \\
\hline
\end{tabular}

\footnotetext{
Values are presented as the mean \pm SD

*: Indicates a significant difference from the $\mathrm{F}$ trial at the same time-point.

s: Significant difference within the trials compared with the 15 min time-point.

Note: RER = Respiratory exchange ratio.
}

may attenuate effort perception by lowering the pain threshold through direct central neural effects [9], but the exact mechanism remains unclear.

Caffeine at the micromolar levels utilised in the present study has been shown to cross the blood brain barrier (BBB) with the potential to serve as a competitive antagonist of adenosine [11]. The net effect would be to increase central DA release by antagonising the inhibition of adenosine $\alpha_{1}$ and $\alpha_{2}$ receptors on DA activity, thus reducing effort perception induced by the exercise-stress [8]. This was consistent with the hypothesis that a high 5-HT:DA ratio may favour increased effort perception and central fatigue, while a low 5-HT:DA ratio may favour increased arousal and motivation [13,14]. Studies using rats for example, found a reduction in brain 5-HT synthesis and in the 5-HT:DA ratio, and an improvement in exercise performance after direct intracerebroventicular caffeine injection [8]. Similar results were found after an attenuation of the enzyme Trp hydroxylase through caffeine administration [10]. In the present experiment however, although effort perception was significantly lower with caffeine exercise performance was not different between the trials. This result suggests a mismatch between effort perception responses and endurance performance during exercise in $10^{\circ} \mathrm{C}$ following caffeine co-ingested with a high fat meal. In addition, a disparity was observed between effort perception and peripheral precursors of brain 5-HT synthesis. Although plasma free[Trp]:[LNAA] ratio was higher with caffeine throughout exercise $(P=0.029)$ (Figure 2$)$, effort perception was significantly lower in the same trial.

The failure of caffeine to significantly affect brain serotonergic function during exercise in the present study is further reflected by the lack of difference in plasma [Prl] (the brain 5-HT and DA metabolic-interaction marker) between the trials. Previous studies have shown that Ketanserin, a 5-HT antagonist drug, reduced Prl release during graded exercise to exhaustion [24,25]. A further study reported that Trp infusion reduced exercise performance and caused an earlier elevation in plasma [Prl] relative to placebo or glucose infusion [26]. In addition, evidence suggests that Prl release is mainly under the control of the central serotonergic system and/or under the hypothalamic 5-HT and DA metabolic interaction [27]. DA for example, has been suggested to be the major Prl-secretion inhibitor factor [28], and 5-HT injection or its ago- 
Table 2: Plasma amino acids concentrations.

\begin{tabular}{|c|c|c|c|c|c|}
\hline \multirow[b]{2}{*}{ Variables } & \multirow[b]{2}{*}{ Trials } & \multicolumn{4}{|c|}{ Blood collection time (min) } \\
\hline & & Rest & $30 \mathrm{~min}$ & $90 \mathrm{~min}$ & End \\
\hline \multirow[t]{3}{*}{ Total $[\operatorname{Trp}]\left(\left.\mu \mathrm{mol} \cdot\right|^{-1}\right)$} & Control & $38 \pm 8$ & $36 \pm 7$ & $39 \pm 3$ & $46 \pm 9$ \\
\hline & $\mathrm{F}$ & $38 \pm 7$ & $39 \pm 7 \S$ & $43 \pm 6^{\S}$ & $42 \pm 9$ \\
\hline & $\mathrm{FC}$ & $38 \pm 7$ & $39 \pm 7$ & $43 \pm 9 \S$ & $43 \pm 7 \S$ \\
\hline \multirow[t]{3}{*}{ [Tyrosine] $\left(\mu \mathrm{mol} \cdot \mathrm{I}^{-1}\right)$} & Control & $54 \pm 8$ & $53 \pm 7$ & $61 \pm 7$ & $71 \pm 8$ \\
\hline & $\mathrm{F}$ & $52 \pm 3$ & $58 \pm 6^{\S}$ & $65 \pm 7 \S$ & $68 \pm 5^{\S}$ \\
\hline & $\mathrm{FC}$ & $51 \pm 4$ & $55 \pm 6^{\S}$ & $64 \pm 8^{\S}$ & $66 \pm 7 \S$ \\
\hline \multirow[t]{3}{*}{ LNAA] $\left(\mu \mathrm{mol} \cdot \mathrm{I}^{-1}\right)$} & Control & $500 \pm 50$ & $487 \pm 35$ & $486 \pm 51$ & $531 \pm 60$ \\
\hline & $\mathrm{F}$ & $522 \pm 46$ & $532 \pm 50$ & $518 \pm 45$ & $518 \pm 54$ \\
\hline & $\mathrm{FC}$ & $505 \pm 40$ & $499 \pm 48$ & $504 \pm 48$ & $506 \pm 44$ \\
\hline \multirow[t]{3}{*}{ Total [Trp]:[LNAA] ratio } & Control & $.076 \pm .013$ & $.077 \pm .012$ & $.081 \pm .009$ & $.088 \pm .016$ \\
\hline & $\mathrm{F}$ & $.072 \pm .012$ & $.074 \pm .013$ & $.083 \pm .015^{\S}$ & $.083 \pm .021$ \\
\hline & $\mathrm{FC}$ & $.075 \pm .012$ & $.080 \pm .013$ & $.085 \pm .013^{\S}$ & $.085 \pm .015^{\S}$ \\
\hline \multirow[t]{3}{*}{ Total [Trp]:[Tyrosine] ratio } & Control & $0.72 \pm .15$ & $0.69 \pm .13$ & $.064 \pm .08$ & $0.66 \pm .11$ \\
\hline & $\mathrm{F}$ & $0.72 \pm .14$ & $0.68 \pm .13^{\S}$ & $0.67 \pm .11$ & $0.63 \pm .15^{\S}$ \\
\hline & FC & $0.74 \pm .17$ & $0.72 \pm .14$ & $0.67 \pm .14$ & $0.65 \pm .10^{\S}$ \\
\hline
\end{tabular}

Values are presented as the mean \pm SD

s: Significant difference within the trials compared with the resting values.

nist precursors and re-uptake inhibitors have been found to increase hypothalamic Prl release and, hence, plasma [Prl] [29]. Consequently, we hypothesised that if caffeine could directly attenuate brain 5 -HT synthesis [10] and/or enhance DA release [8], Prl secretion would be expected to be lower during the exercise trial involving caffeine. The finding of lack of difference in plasma [Prl] between trials may imply that caffeine contributes in reducing effort perception (via a direct brain dopaminergic-mediated effect) but it may not be effective enough to alter neuroendocrine Prl secretion, particularly in trained humans and when exercise is carried out in relatively cold environment. Alternatively, circulating Prl levels may not be a sensitive marker of brain 5-HT [24,25].

Previous studies have demonstrated that elevation in plasma [FFA] displaces Trp from binding to albumin and consequently increases the free-Trp:LNAA ratio into the plasma $[17,18,30,31]$. Since Trp and the other LNAAs share the L-system carrier for crossing the BBB, the elevation in plasma free-Trp:LNAA ratio may favour brain Trp uptake and potentially increase brain 5 -HT synthesis [32], and hence central fatigue [15,33]. A recent study using analbuminaemic rats has shown an improvement in exercise performance after reducing brain Trp uptake by blocking the L-system carrier using 2-aminobicyclo[2,2,1]heptane-2-carboxylic acid, a specific inhibitor of the L-system transporter [34]. Conversely, intracerebroventricular Trp injection in the same species was found to increase $\dot{V}$ and reduce mechanical efficiency and exercise performance in rats [35]. In the present experiment, the free-[Trp]:[LNAA] ratio was significantly higher following caffeine ingestion. This effect may have attributed to the action of caffeine in elevating adipose tissue lipolysis and thus plasma [FFA], results that are consistent with several previous reports (e.g. $[2,3])$. This effect, in conjunction with a reduced effort perception following caffeine ingestion could reflect the two opposing actions of the high fat meal and caffeine interventions. The former potentially increasing 5-HT function and subsequently effort perception [36], and the latter increasing DA function, hence reducing effort perception $[8,14]$. However, although caffeine may have effectively reduced effort perception by possibly elevating brain DA function exercise performance was not enhanced.

Total $\mathrm{CHO}$ and fat oxidation were not different between $\mathrm{F}$ and FC trials. These results help confirm the 
Table 3: Blood glucose, lactate and pyruvate concentrations for each of the three trials.

\begin{tabular}{|c|c|c|c|c|c|c|c|c|c|}
\hline \multirow[b]{2}{*}{ Variables } & \multirow[b]{2}{*}{ Trials } & \multicolumn{8}{|c|}{ Blood collection time (min) } \\
\hline & & Rest & 15 & 30 & 45 & 60 & 75 & 90 & End \\
\hline \multirow[t]{3}{*}{ [Glucose] $\left(\mathrm{mmol} \cdot \mathrm{L}^{-1}\right)$} & Control & $4.9 \pm 0.9$ & $3.8 \pm 0.4$ & $4.1 \pm 0.3$ & $4.2 \pm 0.4$ & $4.0 \pm 0.4$ & $3.9 \pm 0.4$ & $3.9 \pm 0.5$ & $4.1 \pm 1.0$ \\
\hline & $\mathrm{F}$ & $4.7 \pm 0.6$ & $4.1 \pm 0.5$ & $4.4 \pm 0.4^{\S}$ & $4.3 \pm 0.3$ & $4.1 \pm 0.3$ & $3.9 \pm 0.3$ & $3.8 \pm 0.4$ & $3.8 \pm 0.4$ \\
\hline & FC & $4.7 \pm 0.3$ & $4.6 \pm 0.4$ & $4.8 \pm 0.3^{*}$ & $4.8 \pm 0.4^{*}$ & $4.7 \pm 0.4^{*}$ & $4.4 \pm 0.4^{*}$ & $4.3 \pm 0.3^{* \S}$ & $4.1 \pm 0.5^{* \S}$ \\
\hline \multirow[t]{3}{*}{ [Lactate] $\left(\mathrm{mmol} \cdot \mathrm{L}^{-1}\right)$} & Control & $0.8 \pm 0.2$ & $3.6 \pm 1.9$ & $3.4 \pm 2.1$ & $3.5 \pm 2.2$ & $3.6 \pm 2.1$ & $3.8 \pm 2.4$ & $3.5 \pm 1.8$ & $4.5 \pm 1.8$ \\
\hline & $\mathrm{F}$ & $0.8 \pm 0.3$ & $3.4 \pm 0.9$ & $3.1 \pm 1.1$ & $3.0 \pm 1.3^{\S}$ & $2.9 \pm 1.3^{\S}$ & $2.9 \pm 1.2^{\S}$ & $3.1 \pm 1.2$ & $4.1 \pm 2.0$ \\
\hline & FC & $0.8 \pm 0.2$ & $4.1 \pm 1.5^{*}$ & $4.0 \pm 1.8^{*}$ & $3.9 \pm 1.9^{*}$ & $3.8 \pm 1.9^{*}$ & $3.9 \pm 1.9^{*}$ & $3.9 \pm 1.8^{*}$ & $5.1 \pm 2.1^{*}$ \\
\hline \multirow[t]{3}{*}{ [Pyruvate] $\left(\mu \mathrm{mol} \cdot \mathrm{L}^{-}\right)$} & Control & $157 \pm 33$ & $230 \pm 46$ & $218 \pm 50$ & $221 \pm 49$ & $224 \pm 51$ & $228 \pm 48$ & $234 \pm 53$ & $254 \pm 61$ \\
\hline & $\mathrm{F}$ & $159 \pm 33$ & $235 \pm 49$ & $223 \pm 58^{\S}$ & $218 \pm 53$ & $212 \pm 57$ & $215 \pm 44$ & $216 \pm 47$ & $219 \pm 46$ \\
\hline & FC & $163 \pm 41$ & $256 \pm 52$ & $252 \pm 58^{*}$ & $250 \pm 57^{*}$ & $245 \pm 57^{*}$ & $237 \pm 63$ & $239 \pm 61$ & $234 \pm 51$ \\
\hline
\end{tabular}

lack of significant involvement of the brain serotonergic and dopaminergic modulators during this type of exercise. These results also support the role of glycogen depletion in fatigue development during prolonged exercise in well-trained humans in relatively cold environments [22]. However, the role of elevated brain DA levels in the reduction of perceptual responses and improvement in performance during fatiguing exercise in a warm environment is further supported by recent studies. Watson et al. [37] for example, examined the effects of DA and norepinephrine (NE) reuptake inhibitors in a temperate or in a warm condition. These authors suggested that DA reuptake inhibitors was able to reduce effort perception and enhance performance in the heat by superseding hyperthermia-induced inhibitory signals within the central nervous system responsible to terminate exercise trial. Similarly, Roelands et al. [38] examined the effects of methylphenidate, a DA reuptake inhibitor, on exercise performance suggesting that this drug improve 30 minutes time-trial in the heat, but not in normal environmental temperature. As it was mentioned above, in the present study caffeine did not appear to influence substrate utilisation, consequently, no improvement in exercise performance could be reasonably expected, as it is well established that fatigue during prolonged exercise at $10^{\circ} \mathrm{C}$ is due to glycogen depletion [22]. The improvements therefore, in endurance exercise performance observed in previous caffeine studies are unlikely to be associated with glycogen depletion, unless caffeine ingestion altered substrate utilisation. This is the reason why in the present study a time to fatigue protocol, which glyco- gen depletion could be achieved, was employed. Due to the experiment design, in the present study we were able to examine both the metabolic (peripheral) and central (brain neurotransmission modulators and indices) effects of caffeine during prolonged exercise.

Based on the results presented here, one could argue that the lack of performance improvement following caffeine ingestion in conjunction with the reduced effort perception observed is due to either the time to peak plasma caffeine concentration or to individual differences in caffeine uptake. We do not think however, that time to peak plasma concentration had any significant effect on the results since all subjects followed exactly the same experimental procedure prior to each exercise trial. On the other hand, the intra-individual differences in caffeine uptake may elevate type II statistical error in the present and perhaps in other previous studies where caffeine was used as a treatment. This could be evident, if we take into consideration that there may be "responders" and "nonresponders" to various drugs including perhaps caffeine. In a psychophysiological study for example, where the differences between the "responders" and "non-responders" to brain neurotransmission manipulating drug (e.g. brofaromine and fluvoxamine) therapy were examined, it was suggested that some physiological responses (e.g. heart rate and blood pressure responsiveness) to the drugs were different between the two groups, being higher in the "non-responders" than the "responders" to the drug group [39]. Similarly, Kampf-Sherf et al. [40] examined the physiological responses to selective serotonin reuptake inhibitors (SSRI) treatment to depressed 


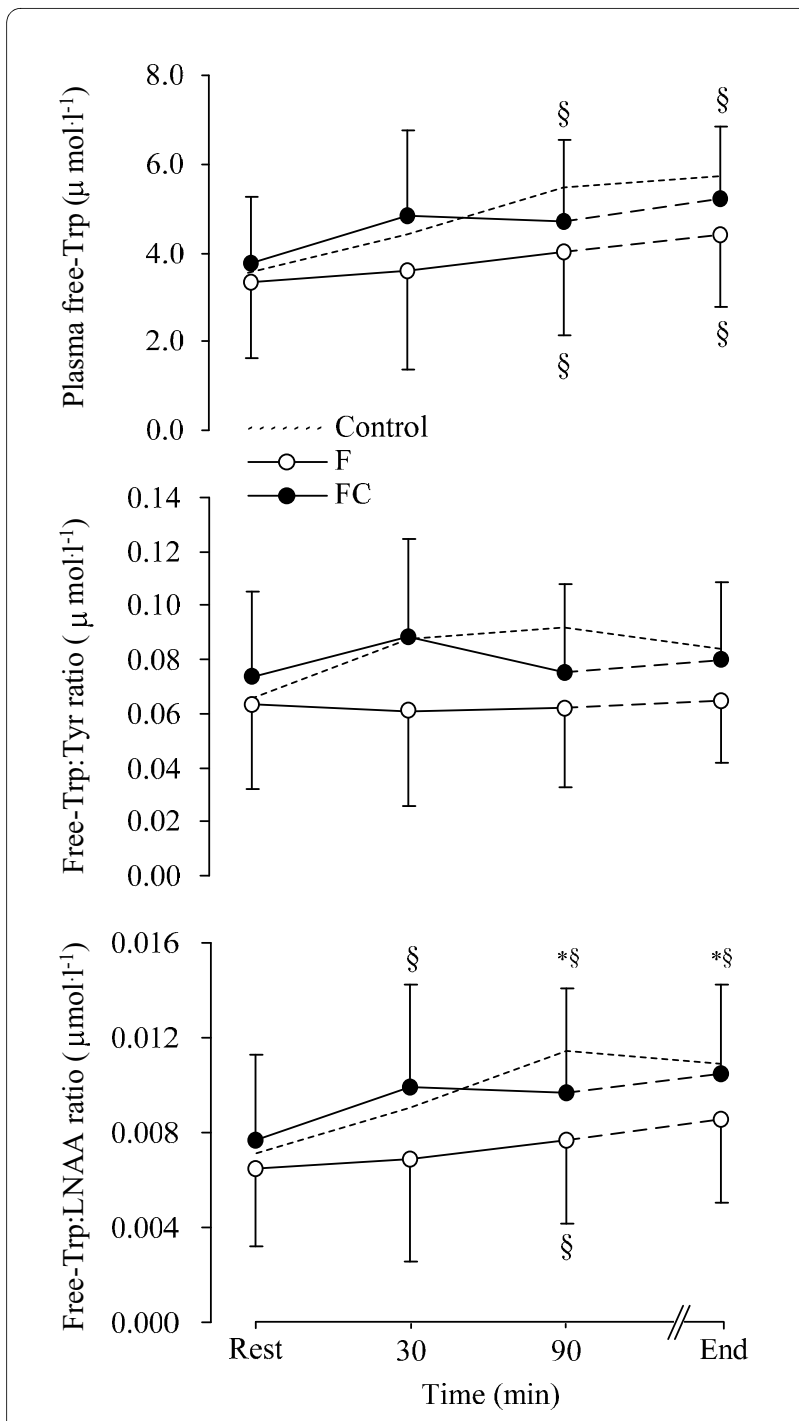

Figure 2 Plasma free-Trp:LNAA ratio (bottom panel), free-Trp:Tyr ratio (middle panel) and plasma free-Trp (top panel). *: indicates a significant difference between the F (white dots) and the FC (black dots) trials. 5 : indicates significant differences within the trials compared with the 15 min time-point. The dash line indicates the Control trial. Values are presented as the mean \pm SD .

patients and they suggested that only two third of patients with major depression have shown physiological responses to antidepressants such as SSRI. In a previous also study, the drug amynophylline was used as a "vehicle" to test the physiological responses as well as adenosine receptors to the drug [41]. These authors suggested that there are "responders" and "non-responders" to the amynophylline and this might be explained by genetic differences in some elements of the adenosine signalling pathway in humans [41]. Consequently, to minimise the effect of this confounding variable on future exercise performance studies, studies may be necessary to try and

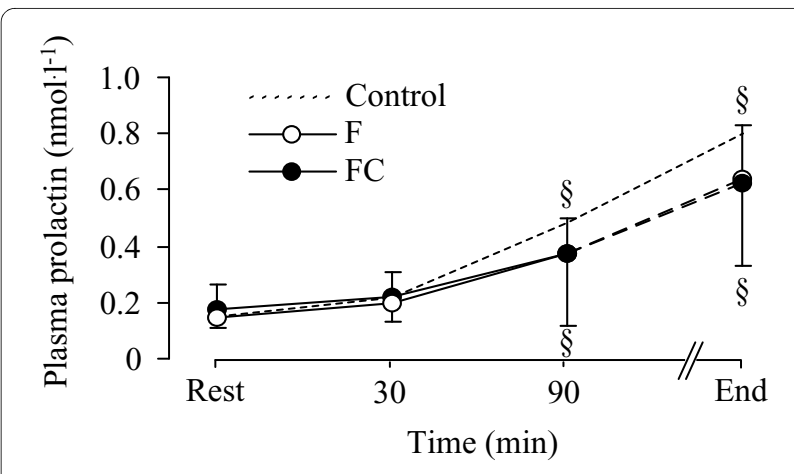

Figure 3 Plasma prolactin responses between the $\mathrm{F}$ (white dots) and the FC (black dots) trials. \$: indicates significant differences within the trials compared with the 15 min time-point. The dash line indicates the Control trial. Values are presented as the mean \pm SD.

identify "responders" and "non-responders" to caffeine prior to starting the experimental trials.

\section{Conclusions}

In conclusion, brain serotonergic and dopaminergic systems are unlikely to be implicated in the fatigue process when exercise is performed without significant thermoregulatory stress, thus enabling fatigue development during endurance exercise to occur predominantly due to glycogen depletion. Consequently, it could be suggested that when artificial elevation in plasma FFA occurs, caffeine does not improve endurance performance either through its potential peripheral metabolic pathway or via its possible central mediated effects (i.e. enhancement of brain dopaminergic system). For practical application purposes we would like to suggest that under the environmental circumstances that our experiment was exe-

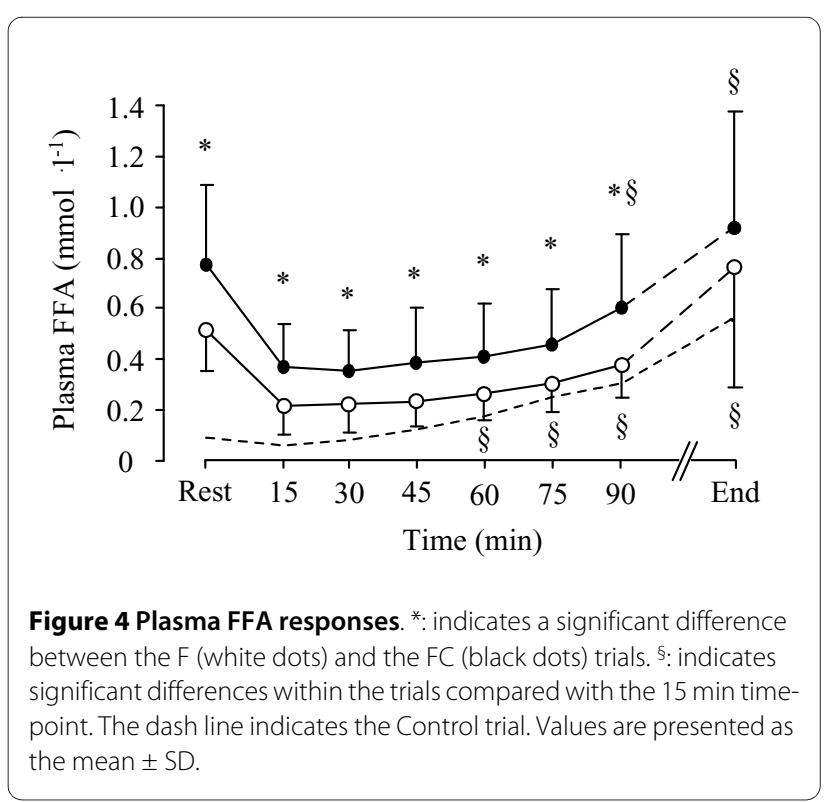


cuted, although caffeine was not found to significantly improve endurance performance, we could recommend that a pre-exercise caffeine ingestion may contribute to enable athletes a) to train with more motivation for progressively achieving elevation or maintenance in their performance and b) to compete with more enthusiasm to the limits of tolerance.

\section{Competing interests}

The authors declare that they have no competing interests.

\section{Authors' contributions}

$\mathrm{MH}$ was the primary author of the manuscript and participated in the design of the study and carried out the data collection, data analysis, statistical analysis and interpretation of the results. LK played an important role in study design, data collection and data interpretation and manuscript preparation. YP played an important role in study design, data collection and interpretation and study coordination. All authors read and approved the final manuscript.

\section{Acknowledgements}

The authors acknowledge Dr Jonathan Fuld for medically screening the subjects and Mrs Heather Collin, Mr Paul Patterson and Mr Robert Auld for their excellent technical assistance. Some of the results obtained from this (series of) experiment(s) related only to peripheral aspects of fatigue have been reported elsewhere from the same authors [42]. The co-operation of the participants is strongly appreciated. The study was partially funded from the Graduate School of the Institute of Biomedical and Life Sciences, Glasgow University, UK.

\section{Author Details}

'Department of Life and Health Sciences, University of Nicosia, Nicosia, Cyprus, 2Integrative and Systems Biology, Faculty of Biomedical and Life Sciences (FBLS), University of Glasgow, Glasgow, UK and ${ }^{3}$ Sport and Exercise Science Research Centre, Vivian Tower, Swansea University, UK

Received: 8 January 2010 Accepted: 27 May 2010

Published: 27 May 2010

\section{References}

1. Chester N, Wojek N: Caffeine consumption amongst British athletes following changes to the 2004 WADA prohibited list. Int J Sports Med 2008, 29:534-528.

2. Costill $D$, Dalsky LGP, Fink WJ: Effects of caffeine ingestion on metabolism and exercise performance. Med Sci Sports 1978, 10:155-158.

3. Spriet LL, MacLean DA, Dyck DJ, Hultman E, Cederblad G, Graham TE: Caffeine ingestion and muscle metabolism during prolonged exercise in humans. Am J Physiol 1992, 262:E891-E898.

4. Cox G, Desbrow R, Montgomery P, Anderson M, Bruce C, Macrides T, Martin D, Moquin A, Roberts A, Hawley J, Burke L: Effect of different protocols of caffeine intake on metabolism and endurance performance. J App/ Physio/ 2002, 93:990-999.

5. Desbrow B, Barrett C, Minahan CL, Grant G, Leveritt M: Caffeine, Cycling Performance, and Exogenous CHO Oxidation: A Dose-Response Study. Med Sci Sports Exerc 2009, 41:1744-1751.

6. Jackman M, Wendling P, Friars D, Graham T: Metabolic catecholamine, and endurance responses to caffeine during intense exercise. J Appl Physiol 1996, 81:1658-1663.

7. O'Rourke MP, O'Brien BJ, Knez WL, Paton CD: Caffeine has a small effect on 5-km running performance of well-trained and recreational runners. J Sci Med Sports 2008, 11:231-233.

8. Davis JM, Zhao Z, Stock HS, Mehl KA, Buggy J, Hand GA: Central nervous system effects of caffeine and adenosine on fatigue. Am J Physiol 2003, 284:R399-R404

9. Tarnopolsky MA: Effect of caffeine on the neuromuscular system potential as an ergogenic aid. Appl Physiol Nutr Metab 2008, 33:1284-1289

10. Lim B-V, Jang M-H, Shin M-C, Kim H-B, Kim Y-J, Kim Y-P, Chung J-H, Kim H, Shin M-S, Kim S-S, Kim E-H, Kim C-J: Caffeine inhibits exercise-induced increase in tryptophan hydroxylase expression in dorsal and median raphe of Sprague-Dawley rats. Neuroscience Letters 2001, 308:25-28.
11. Fredholm BB, Battig K, Holmen J, Nehlig A, Zvartau EE: Actions of caffeine in the brain with special reference to factors that contribute to its widespread use. Pharmacol Rev 1999, 51:83-133.

12. Cole KJ, Costill DL, Starling RD, Goodpaster BH, Trappe SW, Fink WJ: Effect of caffeine ingestion on perception of effort and subsequent work production. Int J Sport Nutr 1996, 6:14-23.

13. Davis JM, Bailey SP, Jackson DA, Strasner AB, Morehouse SL: Effect of a serotonin (5-HT) agonist during prolonged exercise to fatigue in humans. Med Sci Sport Exerc 1993, 25:S78.

14. Davis JM, Bailey SP: Possible mechanisms of central nervous system fatigue during exercise. Med Sci Sports Exerc 1997, 29:45-57.

15. Newsholme E, Acworth IN, Blomstrand E: Amino-acids, brain neurotransmitters and a functional link between muscle and brain that is important in sustained exercise. In Advances in Biochemistry Edited by: Benzi G. UK: John Libby Eurotext; 1987:127-138.

16. De Simoni MG, Sokola A, Fodritto F, Dal Toso G, Algeri S: Functional meaning of tryptophan-induced increase of 5-HT metabolism as clarified by in vivo voltammetry. Brain Research 1987, 411:89-94.

17. Bloxam DL, Tricklebank M, Patel A, Curzon G: Effects of albumin amino acids and clofibrate on the uptake of tryptophan by the rat brain. $J$ Neurochem 1980, 34:43-49.

18. Curzon G, Friedel J, Knott PJ: The effect of fatty acids on the binding of tryptophan to plasma protein. Nature 1973, 242:198-200.

19. Holland B, Welch A, Unwin I, Buss D, Paul A, Southgate D: The Composition of Foods. In Goodfellow Egan Phototypesetting Cambridge, UK; 1991.

20. Bergstrom J, Hermansen L, Hultman E, Saltin B: Diet, muscle glycogen and physical performance. Acta Physio/ Scand 1967, 71:140-150.

21. Forster V, Dempsey J, Thomson J, Vidruk R, DoPico G: Estimation of arterial $\mathrm{PO}_{2}, \mathrm{PCO}_{2}, \mathrm{pH}$ and lactate from arterialised venous blood. $J$ Appl Physiol 1972, 32:134-137.

22. Galloway SDR, Maughan RJ: Effects of ambient temperature on the capacity to perform prolonged cycle exercise in man. Med Sci Sports Exerc 1997, 29:1240-1249.

23. Noble BJ, Borg GA, Jacobs I, Ceci R, Kaiser P: A category-ratio perceived exertion scale: relationship to blood and muscle lactates and heart rate. Med Sci Sports Exerc 1983, 15:523-528.

24. De Meirleir K, L'Hermite-Baleriaux M, L'Hermite M, Rost R, Hollmann W: Evidence for serotoninergic control of exercise-induced prolactin secretion. Horm Metab Res 1985, 17:380-381.

25. De Meirleir K, Baeyens LL, L'Hermite-Baleriaux M, L'Hermite M, Hollmann W: Exercise-induced prolactin release is related to anaerobiosis. $J$ Clin Endocrinol Metab 1985, 60:1250-1252.

26. Farris JW, Hinchcliff KW, McKeever KH, Lamb DR, Thompson DL: Effect of tryptophan and of glucose on exercise capacity of horses. J Appl Physiol 1998, 85:807-816.

27. Ben-Jonathan N, Arbogast LA, Hyde JF: Neuroendocrine [corrected] regulation of prolactin release. Progress in Neurobiol 1989, 33:399-447.

28. Nagy GM, Arendt A, Banky Z, Halasz B: Dehydration attenuates plasma prolactin response to suckling through a dopaminergic mechanism. Endocrinology 1992, 130:819-24.

29. Kar LD Van De, Rittenhouse PA, Li Q, Levy AD: Serotonergic regulation of renin and prolactin secretion. Behaviour \& Brain Res 1996, 73:203-208.

30. Chaouloff F, Elghozi JL, Guezennec Y, Laude D: Effects of conditioned running on plasma, liver and brain tryptophan and on brain 5hydroxytryptamine metabolism of the rat. Br J Pharmacol 1985, 86:33-41.

31. Struder H, Hollmann W, Platen P, Duperly J, Fischer H, Weber K: Alterations in plasma free tryptophan and large neutral amino acids do not affect perceived exertion and prolactin during $90 \mathrm{~min}$ of treadmill exercise. Int J Sports Med 1996, 17:73-79.

32. Pardridge WM: Blood-brain transport of nutrients: Introduction. Fed Proc 1986, 45:2047-2049.

33. Blomstrand E, Celsing F, Newsholme EA: Changes in plasma concentrations of aromatic and branched-chain amino acids during sustained exercise in man and their possible role in fatigue. Acta Physiol Scand 1988, 133:115-121

34. Yamamoto T, Newsholme EA: Diminished central fatigue by inhibition of the L-system transporter for the uptake of tryptophan. Brain Res Bullettin 2000, 52:35-38. 
35. Soares DD, Lima NR, Coimbra CC, Marubayash U: Evidence that tryptophan reduces mechanical efficiency and running performance in rats. Pharmacol Biochem Behav 2003, 74:357-62.

36. Pitsiladis YP, Smith I, Maughan RJ: Increased fat availability enhances the capacity of trained individuals to perform prolonged exercise. Med Sci Sports Exerc 1999, 31:1570-1579.

37. Watson P, Hasegawa H, Roelands B, Piacentini MF, Looverie R, Meeusen R: Acute dopamine/noradrenaline reuptake inhibition enhances human exercise performance in warm, but not temperate conditions. J Physiol 2005, 565(13):873-883.

38. Roelands B, Goekint M, Heyman E, Piacentini MF, Watson P, Hasegawa H, Buyse L, Pauwels F, De Schutter G, Meeusen R: Acute norepinephrine reuptake inhibition decreases performance in normal and high ambient temperature. J Appl Physiol 2008, 105:206-212.

39. Slaap BR, van Vliet IM, Westenberg HGM, Den Boer JA: Responders and non-responders to drug treatment in social phobia: differences at baseline and prediction of response. J Affective Disorders 1996, 39:13-19.

40. Kampf-Sherf O, Zlotogorski Z, Gilboa A, Speedie L, Lereya J, Rosca P, Shavit $Y$ : Neuropsychological functioning in major depression and responsiveness to selective serotonin reuptake inhibitors antidepressants. J Affect Disord 1996, 82:453-9.

41. Martin EA, Nicholson WT, Eisenach JH, Charkoudian N, Joyner MJ: Influences of adenosine receptor antagonism on vasodilator responses to adenosine and exercise in adenosine responders and nonresponders. J Appl Physiol 2006, 101:1678-1684.

42. Hadjicharalambous M, Georgiades E, Kilduff LP, Turner AP, Tsofliou F, Pitsiladis YP: Influence of caffeine on effort perception, metabolism and exercise performance following a high fat meal. J Sports Sci 2006, 24(8):875-887.

doi: $10.1186 / 1550-2783-7-22$

Cite this article as: Hadjicharalambous et al., Brain serotonergic and dopaminergic modulators, perceptual responses and endurance exercise performance following caffeine co-ingested with a high fat meal in trained humans Journal of the International Society of Sports Nutrition 2010, 7:22

Submit your next manuscript to BioMed Central and take full advantage of:

- Convenient online submission

- Thorough peer review

- No space constraints or color figure charges

- Immediate publication on acceptance

- Inclusion in PubMed, CAS, Scopus and Google Scholar

- Research which is freely available for redistribution

Submit your manuscript at www.biomedcentral.com/submit
Ciomed Central 